\title{
Respiratory virus-associated infections in HIV-infected adults admitted to the intensive care unit for acute respiratory failure: a 6-year bicenter retrospective study (HIV-VIR study)
}

\author{
Alexandre Elabbadi ${ }^{1}$, Jérémie Pichon ${ }^{1}$, Benoit Visseaux ${ }^{2,3}$, Aurélie Schnuriger ${ }^{4}$, Lila Bouadma ${ }^{3,5}$, \\ Quentin Philippot ${ }^{1}$, Juliette Patrier ${ }^{5}$, Vincent Labbé ${ }^{1,6}$, Stéphane Ruckly ${ }^{3}$, Muriel Fartoukh ${ }^{1,6}$, \\ Jean-François Timsit ${ }^{3,5}$ and Guillaume Voiriot ${ }^{1,6^{*}}$ (D)
}

\begin{abstract}
Introduction: Acute respiratory failure is the main reason for admission to the intensive care unit (ICU) in HIVinfected adults. There is little data about the epidemiology of respiratory viruses in this population.

Methods: HIV-infected adults admitted to two intensive care units over a 6-year period for an acute respiratory failure and explored for respiratory viruses with multiplex polymerase chain reaction (MPCR) were retrospectively selected. Objectives were to describe the prevalence of respiratory viruses, coinfections with non-viral pathogens, and hospital outcome.

Results: A total of 123 episodes were included. An HIV infection was newly diagnosed in 9\% of cases and $72 \%$ of the population were on antiretroviral therapy. Real-time $\mathrm{mPCR}$ tests identified at least one respiratory virus in the respiratory tract of 33 (27\%) patients, but with a non-viral copathogen in two-thirds of cases. Rhinovirus was predominant, documented in 15 patients, followed by Influenza and Respiratory Syncytial Viruses (both $n=6$ ). The prevalence of respiratory virus-associated infection did not vary along with the level of the CD4 T-cell deficiency, except for Rhinovirus which was more prevalent in patients with a CD4 lymphocyte count below 200 cells $/ \mu \mathrm{L}(n=13$ (20\%) vs. $n=2(4 \%), p<0.01)$. In multivariate analysis, respiratory virus-associated infection was not associated with a worse prognosis.
\end{abstract}

Conclusions: Viruses are frequently identified in the respiratory tract of HIV-infected patients with acute respiratory failure that requires ICU admission, but with a non-viral copathogen in two-thirds of cases. Rhinovirus is the predominant viral specie; its prevalence is highest in patients with a CD4 lymphocyte count below 200 cells $/ \mu \mathrm{L}$.

Keywords: Acute respiratory failure, Human immunodeficiency virus, Polymerase chain reaction, Viral pneumonia, Viral pneumonia

\footnotetext{
*Correspondence: guillaume.voiriot@aphp.fr

${ }^{1}$ Assistance Publique - Hôpitaux de Paris, Service de médecine intensive réanimation, Hôpital Tenon, Sorbonne Université, Paris, France

Full list of author information is available at the end of the article
}

\begin{abstract}
Introduction
Acute respiratory failure (ARF) is the leading cause of admission to the intensive care unit (ICU) in HIVinfected patients [1-3]. Infectious causes are predominant, although the proportion of opportunistic infections has decreased significantly in the era of combination antiretroviral therapy (ART) $[2,4,5]$. In contrast, the
\end{abstract}

\section{Springer Open}

(c) The Author(s) 2020. This article is licensed under a Creative Commons Attribution 4.0 International License, which permits use, sharing, adaptation, distribution and reproduction in any medium or format, as long as you give appropriate credit to the original author(s) and the source, provide a link to the Creative Commons licence, and indicate if changes were made. The images or other third party material in this article are included in the article's Creative Commons licence, unless indicated otherwise in a credit line to the material. If material is not included in the article's Creative Commons licence and your intended use is not permitted by statutory regulation or exceeds the permitted use, you will need to obtain permission directly from the copyright holder. To view a copy of this licence, visit http://creativeco mmons.org/licenses/by/4.0/. 
burden of non-HIV-related pulmonary events, such as bacterial pneumonia, acute bronchitis and acute exacerbation of chronic obstructive pulmonary disease (COPD) has been shown increasing $[2,3,6]$. These important changes in the etiologic panel of ARF in HIV-infected patients question the role of respiratory viruses. Indeed, using nucleic acid amplification test such as multiplex polymerase chain reaction ( $\mathrm{mPCR}$ ), these pathogens have been shown highly prevalent (20-56\%) in large cohorts of adult patients admitted to the ICU for all-cause ARF $[7,8]$, community-acquired pneumonia $[9,10]$, hospitalacquired pneumonia [11], acute exacerbation of COPD $[12,13]$, and asthma [14], compared to asymptomatic adults $[15,16]$. High prevalence has also been described in specific immunocompromised populations, such as cancer and hematology patients $[17,18]$. In contrast, little is known about the epidemiology of respiratory viruses in HIV-infected patients [19, 20], especially those admitted to the ICU, and the prevalence of respiratory viruses according to the CD4 T-cell deficiency. Moreover, coinfections with virus and opportunistic pathogens may occur. Overall, respiratory virus-associated infections may affect prognosis.

Therefore, we conducted a comprehensive observational study among adult HIV-infected ICU patients with ARF explored with respiratory mPCR. Our goals were to describe the prevalence of respiratory viruses, coinfections with non-viral pathogens, and hospital outcome.

\section{Methods}

\section{Study design and patient selection}

We conducted a retrospective bicenter observational study in two ICU of the Paris area (the 26-bed ICU of the Bichat University Hospital and the 20-bed ICU of the Tenon University Hospital). From April 2011 to April 2017, all consecutive HIV-infected patients admitted to ICU having undergone an $\mathrm{mPCR}$ in the respiratory tract within $72 \mathrm{~h}$ following their ICU admission were screened. Medical records were independently reviewed by two physicians (AE and GV). All patients with ARF at ICU admission were included. ARF was defined by the presence of at least two of the following criteria: cough, expectoration, dyspnea, rales, signs of respiratory distress (tachypnea exceeding 30/min, paradoxical abdominal breathing), chest pain, hypoxemia requiring oxygen therapy, noninvasive ventilation or intubation. In case of multiple admissions over the 6-year study period, only the first admission was analyzed.

\section{Data collection}

At ICU admission and during ICU stay, data regarding demographics, comorbidity, HIV-related characteristics, clinical examinations, laboratory and radiological findings, microbiologic investigations, and therapeutic management were collected (for details, see Additional file 1). Mortality was defined as death from any cause within 28 days following the ICU admission.

\section{Microbiological evaluation}

Respiratory mPCRs were performed either in nasopharyngeal (NP) swabs or in lower respiratory tract (LRT) specimen, usually bronchoalveolar lavage (BAL) fluid otherwise endotracheal aspirate. During the study period, different respiratory $\mathrm{mPCR}$ kits (Additional file 1: Table S1) were used (for more details about microbiological evaluation, see Additional file 1).

\section{Classification of patients according to the causative diagnosis of ARF}

Medical charts were independently reviewed by two clinicians ( $\mathrm{AE}$ and GV). They determined the causative diagnosis of ARF for each patient, using a 5-class classification. In case of an inter-reviewer discordance, a shared review of the medical charts was performed, and an agreement was found. The five mutually exclusive classes of causative diagnosis for ARF were: (i) Pneumocystis jirovecii pneumonia (PCP); (ii) other opportunistic lung infections; (iii) non-opportunistic acute lung infection; (iv) non-infectious lung disease, and (v) extra-pulmonary cause (for details, see Additional file 1).

\section{Endpoints}

The primary endpoint was to determine the prevalence of respiratory viruses according to the CD4 lymphocyte count. A respiratory virus documented with $\mathrm{mPCR}$ was always considered as a pathogen of the respiratory tract, regardless of the type of specimen (NP or LRT). The CD4 lymphocyte count measured during the ICU stay was used to group patients, with a cut-off of 200 cells $/ \mu \mathrm{L}$ ( $\leq 200$ cells/ $\mu \mathrm{L}$ for the Low-CD4 group; $>200$ cells/ $\mu \mathrm{L}$ for the High-CD4 group) [19, 21].

Secondary endpoints were to describe the epidemiology of respiratory viruses and coinfections with non-viral pathogens, to identify risk factors for respiratory virusassociated infection, and to study outcome. A composite criterion named "complicated course" included death from any cause within 28 days following the ICU admission or mechanical ventilation for more than 7 days.

\section{Data presentation and statistical analysis}

Continuous data were expressed as median [first through third quartiles] and were compared using the pairwise Mann and Whitney test. Categorical data were expressed as number (percentage) and were evaluated using the chi-square test or Fisher exact test. $p$ values less than 0.05 were considered significant. A univariate logistic 
regression with clinically relevant variables was used to identify variables associated with a respiratory virusassociated infection. A multivariate conditional logistic regression, including variables with $p$ value less than 0.10 in the previous step, was used to identify variables independently associated with a respiratory virus-associated infection. Similar statistical analyses were performed to identify variables independently associated with death from any cause within 28 days following the ICU admission and mechanical ventilation for more than 7 days in survivors at Day-28. Quantitative variables that did not validate the log-linearity assumption were transformed into categorical variables according to their median value. Missing data were imputed to the median or the more frequent value. The accuracy of the final model was tested using area under the receiver operating characteristic curve analysis and the Hosmer-Lemeshow chi-square test. Analyses were performed using the SAS software package (SAS Institute, Cary, NC, USA).

\section{Ethical considerations}

This study was approved by the institutional review board of the French Society of Respiratory Diseases (Reference CEPRO 2018-017) according to the French regulations. The board waived the need for signing consent for patients included in the study.

\section{Results}

\section{Population}

During the 6-year study period, 135 HIV-infected adult patients were admitted at least once to ICU and underwent a respiratory $\mathrm{mPCR}$ in the first $72 \mathrm{~h}$ of the ICU stay. Among them, 12 did not fulfill criteria of ARF. The final study group consisted of 123 patients. Their main characteristics, stratified by the CD4 lymphocyte count at ICU admission, are presented in Table 1 . Of these 123 patients, 2 were admitted twice during the study period and one was admitted thrice. Eleven patients $(9 \%)$ were newly diagnosed as having HIV infection on ICU admission; the remaining 112 had been previously diagnosed, and 88 were on ART but with poor adherence to the treatment in 21 patients, as mentioned by the infectiologist in the medical charts. Latest available median CD4 lymphocyte count and HIV viral load were 351 cells $/ \mu \mathrm{L}$ [140-600] and $0 \log$ copies/mL [0-3.4], respectively. At least one additional factor of immunosuppression was identified in $10(8 \%)$ patients.

At ICU admission, median CD4 lymphocyte count was 170 cells/ $\mu \mathrm{L}$ [20-430], with 66 patients (54\%) equal or below 200 cells $/ \mu \mathrm{L}$ (Low-CD4 group) and 57 (46\%) above 200 cells/ $\mu \mathrm{L}$ (High-CD4 group). Both these groups did not differ regarding demographics, performance status, factors of immunosuppression other than HIV and comorbidity, except for COPD which was more prevalent in the High-CD4 group $(n=12(21 \%)$ vs. $n=4(6 \%)$, $p=0.01)$.

\section{Microbiological investigations}

The microbiological investigations are displayed in Additional file 1: Table S2. mPCR was performed in NP swabs exclusively $(n=46,37 \%)$ or in LRT specimen exclusively $(n=50,41 \%)$, or both $(n=27,22 \%)$. Respiratory tract specimens for bacterial culture have been obtained in $110(91 \%)$ patients. BAL fluid has been obtained in 77 (63\%) patients.

\section{Causative diagnosis of ARF}

Causative diagnoses of ARF are displayed in Table 2. An opportunistic lung infection was diagnosed in 38 (31\%) patients. Seven of the 11 patients with newly diagnosed HIV infection and 8 patients receiving ART, but with a poor adherence to the treatment had PCP.

Non-opportunistic acute lung infections were identified as causative diagnosis of ARF in 59 (48\%) patients. All the bacteria-infected patients received an appropriate antimicrobial regimen within the first $24 \mathrm{~h}$ of ICU stay. Eight patients had a clinical presentation suggestive of lung infection, but without microbiological documentation.

The ARF was attributed to a non-infectious lung disease in $19(15 \%)$ patients, mainly related to a decompensated chronic condition, i.e., acute exacerbation of COPD and pulmonary edema.

\section{Analysis according to the viral diagnosis}

Overall, 36 respiratory viruses were identified in 33 (27\%) patients (Table 3$)$. Rhinovirus was predominant $(n=15)$, followed by Influenza $(n=6)$, Respiratory Syncytial Virus $(n=6)$ and Parainfluenza Virus $(n=5)$. Only one pure virus-virus coinfection was found.

The prevalence of respiratory virus-associated infection did not differ among Low- and High-CD4 groups (Table 1); therefore, the median CD4 lymphocyte count in respiratory virus-infected patients was 109 [16-420] cells $/ \mu \mathrm{L}$, in comparison with 192 [27-428] cells $/ \mu \mathrm{L}$ in non-infected patients (Fig. 1). However, the prevalence of Rhinovirus-associated infection was higher in the LowCD4 group, and three-quarters of Rhinovirus-infected patients exhibited a CD4 lymphocyte count below 200 cells/ $\mu \mathrm{L}$ (Fig. 2).

In 22 patients, the viral documentation was accompanied by a non-viral documentation (Additional file 1: Figure S1), with bacteria-virus coinfection in 11 patients, bacteria-virus-virus in 2 patients, $P$. jirovecii-virus in 7 patients and $P$. jirovecii-virus-virus in one patient. 
Table 1 Baseline characteristics, behavior during ICU stay, and outcome of $123 \mathrm{HIV}$-infected patients admitted to the ICU for acute respiratory failure, according to the CD4 lymphocyte count on the ICU admission

\begin{tabular}{|c|c|c|c|c|}
\hline Patients & All patients $(n=123)$ & $\mathrm{CD} 4 \leq 200(n=66)$ & CD4 $>200(n=57)$ & $\begin{array}{l}p \\
\text { value }^{a}\end{array}$ \\
\hline Age (year) & $51[43-59]$ & $46[39-56]$ & 55 [47-59] & $<0.01$ \\
\hline Sex male & $82(66.7)$ & $40(60.6)$ & $42(73.7)$ & 0.12 \\
\hline Smoking & $49(41.2)$ & $24(38.7)$ & $25(43.9)$ & 0.57 \\
\hline WHO performance status $>0$ & $61(50.8)$ & $33(50.7)$ & $28(50.9)$ & 0.99 \\
\hline COPD GOLD III-IV & $16(13)$ & $4(6.1)$ & $12(21.1)$ & 0.01 \\
\hline Arterial hypertension & $32(26)$ & $13(19.7)$ & $19(33.3)$ & 0.09 \\
\hline Coronary heart disease & $19(15.4)$ & $10(15.2)$ & $9(15.8)$ & 0.92 \\
\hline \multicolumn{5}{|l|}{ Baseline HIV-related characteristics } \\
\hline Newly diagnosed HIV infection & $11(8.9)$ & $10(15.2)$ & $1(1.8)$ & 0.92 \\
\hline HIV viral load $(\log )^{b}$ & $0[0-3.4]$ & $4.7[1.2-5.4]$ & $0[0-1.4]$ & $<0.01$ \\
\hline CD4 lymphocyte count (cells/ $\mathrm{LL})^{\mathrm{c}}$ & 351 [140-600] & 72 [30-200] & $517[406-715]$ & $<0.01$ \\
\hline ART & $88(72.1)$ & $33(50.8)$ & $55(96.5)$ & $<0.01$ \\
\hline Steroid therapy ${ }^{d}$ & $4(3.3)$ & $2(3)$ & $2(3.5)$ & 0.85 \\
\hline Other immunosuppressive treatments & $2(1.6)$ & $1(1.5)$ & $1(1.8)$ & 0.92 \\
\hline Splenectomy & $1(0.8)$ & 0 & $1(1.8)$ & 0.28 \\
\hline Cancer or hematologic malignancy & $6(4.9)$ & $1(1.5)$ & $5(8.8)$ & 0.06 \\
\hline Chemotherapy & $2(1.6)$ & $1(1.5)$ & $1(1.8)$ & 0.92 \\
\hline Organ/bone marrow transplantation & $(0.8)$ & $1(1.5)$ & 0 & 0.35 \\
\hline Transfer from another ward ${ }^{e}$ & $62(50.4)$ & $30(45.5)$ & $32(56.2)$ & 0.24 \\
\hline SOFA score & $4[2-7]$ & $4[2-8]$ & $3[2-6]$ & 0.60 \\
\hline SAPS II score & $44[34-57]$ & $44[37-57]$ & $41[31-55]$ & 0.20 \\
\hline \multicolumn{5}{|l|}{ Biology on ICU admission } \\
\hline HIV viral load $(\log )^{f}$ & $2.5[0-5.3]$ & $5[2.9-5.6]$ & $0[0-2]$ & $<0.01$ \\
\hline CD4 lymphocyte count (cells/ $\mu \mathrm{L}$ ) & $170[20-430]$ & 29 [10-102] & $461[345-533]$ & $<0.01$ \\
\hline Neutrophil count (G/L) & $6.7[3.9-9]$ & $5.5[2.1-7.6]$ & $7.6[5.3-12.1]$ & $<0.01$ \\
\hline Procalcitonin $(\mu \mathrm{g} / L)^{9}$ & $0.6[0.2-5.9]$ & $0.6[0.2-3]$ & $0.5[0.1-8.3]$ & 0.89 \\
\hline Lactate dehydrogenase (U/L) & $403[276-637]$ & $471[325-675]$ & $327[233-575]$ & 0.02 \\
\hline \multicolumn{5}{|l|}{ Organ supports during ICU stay } \\
\hline High-flow nasal cannula oxygen & $36(29.2)$ & $24(36.3)$ & $12(21)$ & 0.06 \\
\hline Noninvasive ventilation & $30(24.8)$ & $11(17.1)$ & $19(33.3)$ & 0.04 \\
\hline Mechanical ventilation & $43(35.2)$ & $24(36.9)$ & $19(33.3)$ & 0.68 \\
\hline Vasopressor & $36(29.3)$ & $22(33.3)$ & $14(24.6)$ & 0.29 \\
\hline Renal replacement therapy & $23(18.7)$ & $14[21.2)$ & $9(15.8)$ & 0.44 \\
\hline \multicolumn{5}{|l|}{ Outcome } \\
\hline ICU length of stay (day) & $7[4-12]$ & $7[3.3-16.8]$ & $6[3-11]$ & 0.21 \\
\hline Day-28 mortality ${ }^{h}$ & $15(12.2)$ & $8(12.1)$ & $7(12.3)$ & 0.98 \\
\hline Complicated course $^{i}$ & $30(24.4)$ & $17(25.8)$ & $13(22.8)$ & 0.70 \\
\hline
\end{tabular}

Data are presented as median [first through third quartiles] or number (\%). CD4 refers to CD4 lymphocyte count (cells/ $\mu \mathrm{L}$ )

HIV Human immunodeficiency virus, ICU Intensive care unit, SAPS II Simplified Acute Physiologic Score II, SOFA Sepsis-related Organ Failure Assessment, WHO World Health Organization

a P values refer to differences between Low-CD4 ( $<200$ cells $/ \mu \mathrm{L})$ and High-CD4 (> 200 cells/ $\mu \mathrm{L})$ groups in univariate logistic regression

b Data were available for 76 patients

c Data were available for 81 patients

$\mathrm{d} \geq 10 \mathrm{mg}$ of prednisone (or equivalent) per day for more than 30 days

e Transfer from another ward included transfers from another ICU and from the medical wards

f Data were available for 101 patients

9 Data were available for 79 patients

h Mortality was defined as death from any cause within 28 days following the ICU admission

i Complicated course was defined as death from any cause within 28 days following the ICU admission and/or mechanical ventilation $>7$ days 
Table 2 Causative diagnosis of acute respiratory failure in 123 HIV-infected patients admitted to the ICU

\begin{tabular}{|c|c|c|c|}
\hline Patients & All patients $(n=123)$ & $\mathrm{CD} 4 \leq 200(n=66)$ & $\mathrm{CD} 4>200(n=57)$ \\
\hline Pneumocystis jirovecii pneumonia & $29(23.6)$ & $26(39.4)$ & $3(5.3)$ \\
\hline Other opportunistic lung infection ${ }^{a}$ & $9(7.3)$ & $7(10.6)$ & $2(3.5)$ \\
\hline Non-opportunistic acute lung infection & $59(48)$ & $22(33.3)$ & $37(64.9)$ \\
\hline Bacteria & 53 & 21 & 32 \\
\hline Streptococcus pneumoniae & 14 & 9 & 5 \\
\hline Other Streptococcus & 3 & 1 & 2 \\
\hline Staphylococcus aureus & 9 & 5 & 4 \\
\hline Legionella pneumophila & 3 & 0 & 3 \\
\hline Haemophilus influenzae & 2 & 0 & 2 \\
\hline Moraxella catarrhalis & 1 & 0 & 1 \\
\hline Klebsiella pneumoniae/Escherichia coli & 2 & 0 & 2 \\
\hline Other enterobacteria & 5 & 1 & 4 \\
\hline Pseudomonas aeruginosa & 9 & 4 & 5 \\
\hline Other Gram-negative bacteria & 1 & 1 & 0 \\
\hline Mycoplasma pneumoniae & 1 & 0 & 1 \\
\hline Anaerobes & 1 & 0 & 1 \\
\hline Other bacteria & 2 & 0 & 2 \\
\hline Virus & 25 & 13 & 12 \\
\hline Rhinovirus & 8 & 6 & 2 \\
\hline Adenovirus & 2 & 1 & 1 \\
\hline Coronavirus & 1 & 1 & 0 \\
\hline Influenza virus & 6 & 2 & 4 \\
\hline Human metapneumovirus & 1 & 0 & 1 \\
\hline Parainfluenza virus & 3 & 2 & 1 \\
\hline Respiratory syncytial virus & 4 & 1 & 3 \\
\hline Bacteria-virus coinfection & 12 & 8 & 4 \\
\hline Virus-virus coinfection & 2 & 2 & 0 \\
\hline Undocumented & 8 & 2 & 6 \\
\hline Non-infectious lung disease ${ }^{b}$ & $19(15.4)$ & $5(7.6)$ & $14(24.6)$ \\
\hline Extra-pulmonary cause ${ }^{c}$ & $7(5.7)$ & $6(9.1)$ & $1(1.8)$ \\
\hline
\end{tabular}

Data are presented as number (\%). CD4 refers to CD4 lymphocyte count (cells/ $\mu \mathrm{L}$ )

a Other opportunistic lung infections included CMV-associated pneumonia $(n=5)$ and pulmonary tuberculosis $(n=4)$

b Non-infectious lung diseases included acute exacerbation of COPD of non-infectious etiology $(n=6)$, cardiogenic lung edema without underlying lung agent $(n=5)$, cryptogenic hemoptysis $(n=1)$, intra-alveolar hemorrhage $(n=1)$; acute interstitial pneumonia $(n=2)$, Mendelson syndrome $(n=1)$, sickle cell disease (acute chest syndrome) $(n=1)$; neoplastic pleural effusion $(n=1)$ and Castleman disease $(n=1)$

c Extra-pulmonary causes included histoplasmosis $(n=1)$, Cryptococcus neoformans meningitis $(n=1)$, bacterial meningitis $(n=2)$, pyelonephritis $(n=2)$ and bacteremia of unknown origin $(n=1)$

The rate of viral documentation among patients explored with NP swab exclusively, LRT specimen exclusively, or both, did not differ significantly $(30 \%, 26 \%$ and $22 \%$, respectively; $p=0.73$ ).

Documentation of respiratory viruses was more frequent during the winter period (October to March) (Additional file 1: Figure S2). Conversely, Rhinovirus documentation did not follow a seasonal distribution, since only $7 / 15$ were observed during the period from October to March.

Characteristics of the population, stratified by respiratory virus-associated infection are presented in
Additional file 1: Table S3. At ICU admission, respiratory virus-infected patients displayed higher respiratory rate and fever. In multivariate analysis, female gender, smoking and steroid therapy were shown as independently associated with respiratory virus-associated infection (Table 4).

\section{Outcome}

Mortality at Day- 28 was $12 \%$, and $26 \%$ of patients displayed a complicated course, without difference between High-CD4 and Low-CD4 groups (Table 1). We investigated whether a respiratory virus-associated infection 
Table 3 Description of respiratory virus-associated infections and coinfections with non-viral pathogens

\begin{tabular}{|c|c|c|c|c|c|c|c|}
\hline Respiratory viruses & $\begin{array}{l}\text { Rhinovirus } \\
(n=15)\end{array}$ & $\begin{array}{l}\text { Influenza } \\
\text { virus }(n=6)\end{array}$ & $\begin{array}{l}\text { Parainfluenza } \\
\text { virus }(n=5)\end{array}$ & $\operatorname{RSV}(n=6)$ & $\begin{array}{l}\text { Coronavirus } \\
(n=1)\end{array}$ & $\begin{array}{l}\text { Adenovirus } \\
(n=2)\end{array}$ & $\operatorname{hMPV}(n=1)$ \\
\hline $\begin{array}{l}\text { Coinfection with at least one } \\
\text { non-viral pathogen }{ }^{\mathrm{a}}\end{array}$ & 11 & 3 & 3 & 4 & 0 & 2 & 0 \\
\hline Streptococcus pneumoniae & 1 & 2 & 1 & 0 & 0 & 0 & 0 \\
\hline Streptococcus sp. & 0 & 0 & 0 & 1 & 0 & 0 & 0 \\
\hline Staphylococcus aureus & 2 & 2 & 0 & 0 & 0 & 0 & 0 \\
\hline Enterobacteria & 1 & 0 & 0 & 1 & 0 & 1 & 0 \\
\hline Pseudomonas aeruginosa & 3 & 0 & 0 & 1 & 0 & 0 & 0 \\
\hline Corynebacterium sp. & 0 & 0 & 0 & 0 & 0 & 1 & 0 \\
\hline Mycobacterium tuberculosis & 2 & 0 & 0 & 0 & 0 & 0 & 0 \\
\hline Pneumocystis jirovecii & 4 & 0 & 2 & 2 & 0 & 0 & 0 \\
\hline
\end{tabular}

RSV Respiratory Syncytial Virus, hMPV human Metapneumovirus

a Some viruses had several non-viral copathogens

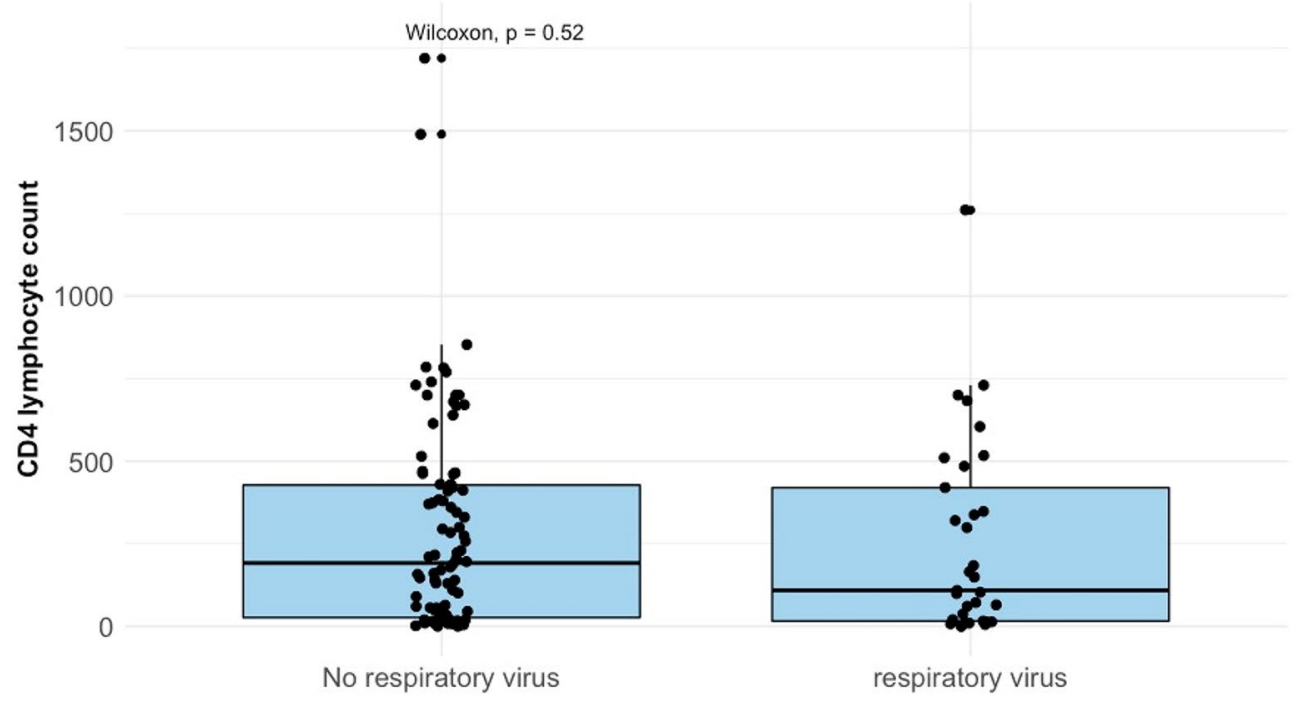

Fig. 1 Diagnosis of respiratory virus-associated infection according to the CD4 lymphocyte count on the ICU admission

affected prognosis. In the analysis stratified by respiratory virus-associated infection, outcome was similar between infected and non-infected patients (Additional file 1: Table S3). In multivariate analysis, a respiratory virus-associated infection was not identified as an independent factor of either a complicated course (Table 5) or death at Day-28 (Additional file 1: Table S4).

\section{Discussion}

This retrospective study investigated the epidemiology of respiratory viruses in HIV-infected adults admitted to the ICU for ARF. Real-time mPCR tests identified at least one virus in the respiratory tract of $27 \%$ of patients, but with a non-viral copathogen in two-thirds of cases. The prevalence of respiratory virus-associated infection did not vary along with the level of the CD4 T-cell deficiency, except for Rhinovirus which was more prevalent in patients with a CD4 lymphocyte count below 200 cells/ $\mu \mathrm{L}$. In multivariate analysis, respiratory virus-associated infection was not associated with a worse prognosis.

In this study, more than one patient out of four (27\%) were infected with at least one respiratory virus. This finding illustrated the high yield of an aggressive diagnostic strategy with a broad panel mPCR on respiratory tract specimens. Our results are original since prior works having described the etiological panel of ARF in HIVinfected ICU patients were conducted before the era of real-time $\mathrm{mPCR}[2,4,22]$. Interestingly, the rate of viral 


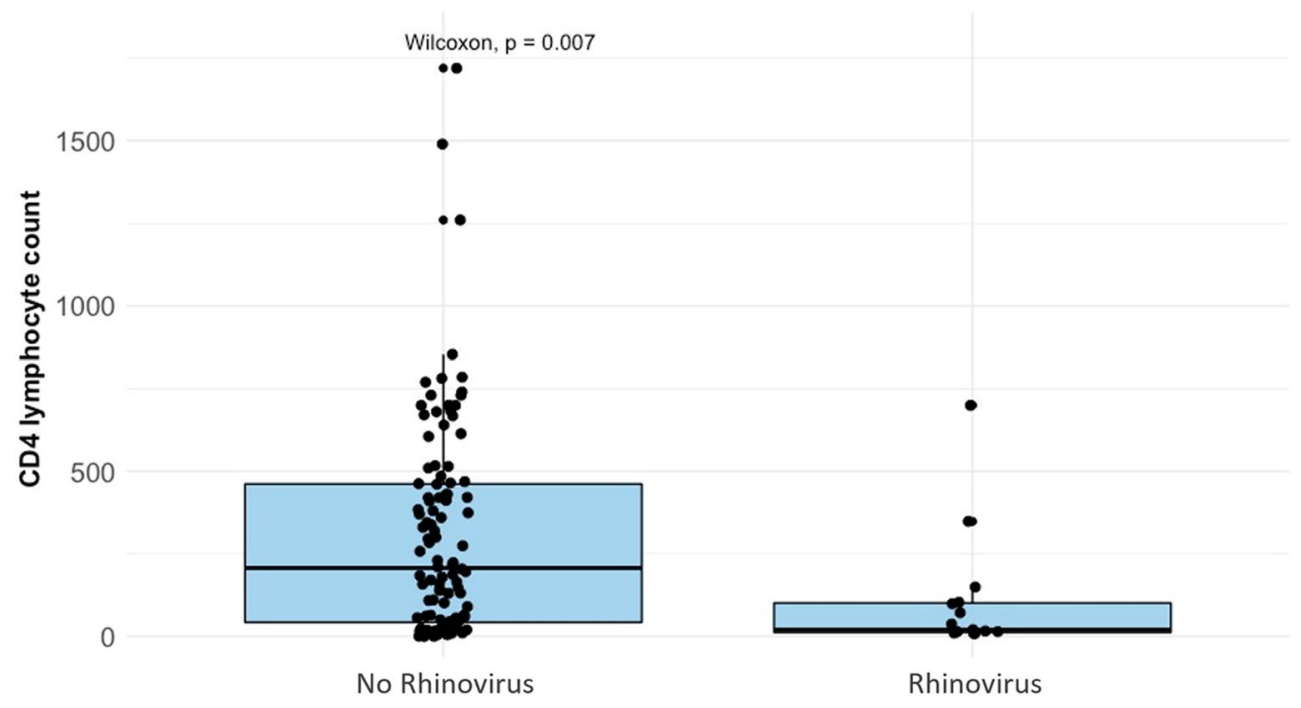

Fig. 2 Diagnosis of Rhinovirus-associated infection according to the CD4 lymphocyte count on the ICU admission

Table 4 Multivariate analysis of the risk factors for respiratory virus-associated infection in $123 \mathrm{HIV}$-infected patients admitted to the ICU for acute respiratory failure

\begin{tabular}{|c|c|c|c|c|c|c|}
\hline \multirow[t]{2}{*}{ Variables } & \multicolumn{3}{|c|}{ Univariate analysis } & \multicolumn{3}{|c|}{ Multivariate analysis } \\
\hline & Odds ratio & $\begin{array}{l}95 \% \text { confidence } \\
\text { interval }\end{array}$ & $p$ value & Odds ratio & $\begin{array}{l}95 \% \text { confidence } \\
\text { interval }\end{array}$ & $p$ value \\
\hline Female gender & 2.45 & {$[1.07-5.59]$} & 0.03 & 2.8 & {$[1.1-7.1]$} & 0.03 \\
\hline Smoking & 2.1 & {$[0.9-4.8]$} & 0.07 & 3.6 & [1.4-9] & 0.007 \\
\hline Steroid therapy & 8.9 & [0.9-88.8] & 0.06 & 18.3 & {$[1.4-236]$} & 0.03 \\
\hline Maximal temperature ${ }^{\mathrm{a}}$ & 1.4 & {$[1.01-2]$} & 0.04 & & & \\
\hline Maximal respiratory rate ${ }^{a}$ & 1.06 & {$[1-1.12]$} & 0.04 & & & \\
\hline Leucocyte count $^{\mathrm{a}}$ & 0.9 & {$[0.81-0.97]$} & $<0.01$ & 0.9 & {$[0.7-0.9]$} & 0.004 \\
\hline Neutrophil count ${ }^{\mathrm{a}}$ & 0.9 & {$[0.79--0.98]$} & 0.02 & & & \\
\hline Lymphocyte count $^{\mathrm{a}}$ & 0.59 & {$[0.33--1.06]$} & 0.08 & & & \\
\hline
\end{tabular}

a Refers to values on the ICU admission

documentation that we observed was similar to what had been described (27 to $29 \%$ ) previously in non-HIV adults admitted to the ICU for an acute respiratory disorder requiring intubation $[7,8]$.

We identified at least one non-viral copathogen in more than two-thirds of the patients with a viral documentation, in line with a recent report in a population with a high prevalence of tuberculosis [19, 23]. Nonopportunistic acute lung infections, including pneumonia, acute bronchitis and exacerbation of COPD, were the first cause of ARF, consistent with previous reports in Western countries [2, 4]. This finding highlights the burden of chronic respiratory conditions in aging HIVinfected populations [6]. Here, more than $40 \%$ of patients were smokers. Synergistic effects of tobacco and HIV [24] in promoting chronic bronchitis and pro-COPD changes in the lung [25] have been demonstrated. Moreover, high rates of viral documentation within airways of COPD patients both at stable state and during exacerbation have been reported [26]. These data may explain the high rate of viral documentation that we observed. In multivariate analysis, smoking was independently associated with respiratory virus-associated infection. This finding is in line with previous works demonstrating that tobacco exposure alters immune responses to Rhinovirus [27], Influenza Virus [28] and Respiratory Syncytial Virus [29]. Interestingly, female gender was associated with an increased risk of respiratory virus-associated infection on multivariate analysis. Prior cohort studies in primary care described an increased risk for development of 
Table 5 Multivariate analysis of the risk factors for complicated course in 123 HIV-infected patients admitted to the ICU for acute respiratory failure

\begin{tabular}{|c|c|c|c|c|c|c|}
\hline \multirow[b]{2}{*}{ Variables } & \multicolumn{3}{|c|}{ Univariate analysis } & \multicolumn{3}{|c|}{ Multivariate analysis } \\
\hline & Odds ratio & $\begin{array}{l}95 \% \text { confidence } \\
\text { interval }\end{array}$ & $p$ value & Odds ratio & $\begin{array}{l}95 \% \text { confidence } \\
\text { interval }\end{array}$ & $p$ value \\
\hline Chronic dialysis & 3.1 & {$[0.73-13.15]$} & 0.12 & & & \\
\hline Cirrhosis (Child B-C) & 2.76 & {$[0.49-15.65]$} & 0.25 & & & \\
\hline Cancer or hematologic malignancy & 2.76 & {$[0.49-15.65]$} & 0.25 & & & \\
\hline Use of vasopressor ${ }^{\mathrm{a}}$ & 7.76 & {$[1.71-35.29]$} & $<0.01$ & 7.2 & {$[1.5-35.4]$} & 0.01 \\
\hline Pleural effusion & 2.34 & {$[0.68-8.1]$} & 0.18 & 3.6 & {$[1.06-12.2]$} & 0.04 \\
\hline HIV viral load ${ }^{b}$ & 1.14 & {$[0.89-1.45]$} & 0.31 & & & \\
\hline $\mathrm{PaO} 2 / \mathrm{FIO} 2$ ratio $^{\mathrm{b}}$ & 0.995 & {$[0.99-1]$} & 0.05 & & & \\
\hline Urea $^{\mathrm{b}}$ & 1.035 & {$[1-1.07]$} & 0.06 & & & \\
\hline Alkaline phosphatase ${ }^{b}$ & 1.008 & {$[1-1.01]$} & $<0.01$ & 1.008 & {$[1.002-1.01]$} & 0.006 \\
\hline Minimal platelet count ${ }^{b}$ & 0.996 & {$[0.99-1]$} & 0.05 & & & \\
\hline Fibrinogen ${ }^{b}$ & 0.79 & {$[0.59-1.06]$} & 0.12 & & & \\
\hline Minimal prothrombin time ${ }^{b}$ & 0.979 & [0.95-1.01] & 0.12 & & & \\
\hline
\end{tabular}

Complicated course was defined as death from any cause within 28 days following the ICU admission and/or mechanical ventilation $>7$ days

a During the first hour of the ICU stay

b Refers to values at ICU admission

Influenza-like illnesses in women compared to men [30, 31]. However, to our knowledge, no prior study has specifically explored this point in HIV-infected populations admitted for ARF.

In this study, we also aimed to investigate a putative role of the HIV-related CD4 T-cell deficiency in promoting respiratory virus-associated infection. Previous studies explored this point in children, but with conflicting results. Annamalay et al. described similar rates of viral documentation in HIV-infected and non-infected children admitted for lower respiratory tract infections [32], whereas O'Callaghan-Gordo et al. observed that respiratory virus-associated infections were 6 to 16 times more prevalent among HIV-infected children admitted for pneumonia [33]. As we did not include a comparative non-HIV population, we rather examined whether or not the rate of viral documentation varied along with the level of CD4 T-cell deficiency. Finally, we found no association between the CD4 lymphocyte count and the risk of respiratory virus-associated infection, in line with a previous report focusing on Influenza viruses [34].

Rhinovirus was the predominant virus, accounting for more than $40 \%$ of viral documentations. This high prevalence was consistent with that of previous reports in ICU patients with ARF [7], community-acquired pneumonia [35] or acute exacerbation of COPD [13]. Surprisingly, Rhinovirus was much more prevalent in low-CD4 patients. This finding is original, since no prior work has specifically explored this point in adults. In HIV-infected children, Rhinovirus has been shown highly prevalent, during both pneumonia and bronchiolitis, but without data regarding a putative association with the level of CD4 T-cell deficiency [32, 36]. Other data in hematology and cancer adults demonstrated high rates of Rhinovirus documentation within airways during respiratory tract infections $[37,38]$. To explain this high prevalence in immunocompromised patients, a mechanism of prolonged viral shedding has been proposed, rather than iterative reinfections as observed in COPD patients [39]. The prolonged Rhinovirus shedding may be attributable to an inefficient immunological control of a single infectious episode [40, 41]. Therefore, in pediatric hematopoietic stem cell transplant recipients with a persistent Rhinovirus shedding ( $\geq 30$ days), Piralla et al. demonstrated significant lower CD4, CD8 and NK lymphocyte counts at the onset of infection, as compared to children with a brief Rhinovirus shedding. Moreover, a decrease in Rhinovirus load was associated with significant increases of the same lymphocyte counts [42]. These data would suggest an important role for the T-cell immunity in the control of Rhinovirus infection, and subsequently, may explain a delayed Rhinovirus clearance in low-CD4 HIVinfected patients, resulting in persistent shedding and increased prevalence.

We observed a high rate of dual infection, either virusbacteria or virus-opportunistic pathogen. These findings made us consider the prognostic impact of such coinfections. Studies in ICU adult patients with pneumonia suggested that virus-bacteria coinfection was associated with a worse prognosis [43]. In mice, the coinfection of 
Influenza with Streptococcus pneumoniae [44], Legionella pneumophila [45] or Staphylococcus aureus [46] impaired the anti-Influenza immune response and increased mortality. Whether similar synergistic effects exist in virusopportunistic pathogen coinfection remain unknown. Only one animal study has explored the couple Pneumocystis jirovecii-Influenza, but in a successive rather than concomitant model [47]. Unfortunately, in our study, the low number of observations prevented us from analyzing the prognosis according to the presence of coinfections.

Our study has several limitations. First, this study included adult patients with ARF that required ICU admission, preventing any conclusion on other populations such as HIV-infected children or HIV-infected adults with ARF that did not require ICU admission. Second, the study was retrospective, so we did not control the microbiological investigations. The preferred sample for MPCR test in non-intubated patients was not the sputum, but the nasopharyngeal swab [48]. Several factors may have discouraged clinicians to use sputum, including the high number of patients unable to produce sputum [49] and the highly viscous nature of this sample that can make nucleic acid extraction difficult [50]. By definition, an mPCR was performed in the respiratory tract of every included patient because it was a criterion for patient screening. But some other microbiological tests were only occasionally performed, i.e., cytomegalovirus PCR. Furthermore, the retrospective design prevented us from obtaining a number of data, which were rarely reported in medical records by physicians, including vaccine history, Pneumocystis jirovecii prophylaxis, symptoms before hospital referral, and duration of symptoms before ICU admission. Third, only patients having undergone an MPCR in the respiratory tract within the $72 \mathrm{~h}$ following their ICU admission were screened; this might suggest a confounding of indication. Fourth, the choice to classify patients according to their CD4 lymphocyte count on the ICU admission, instead of the latest known value, might be criticized. However, this choice was guided by the high number of missing values in the latest CD4 lymphocyte count as well as the number of newly diagnosed patients without any prior CD4 lymphocyte count. Fifth, we assumed that a virus identified with PCR in nasopharyngeal or lower respiratory tract samples was always a pathogen of the respiratory tract, whatever the clinical picture and radiological features. This might be criticized since respiratory viruses might be present in asymptomatic adult subjects [15], even if it seems rare, about $2 \%$ of asymptomatic adults seen at the emergency department [16]. Sixth, to avoid overinterpreting the data, we decided to consider respiratory viruses as a homogeneous group of pathogens in the analysis stratified by respiratory virus-associated infection. This might be criticized since the pathogenicity differs from one viral species to another.

\section{Conclusions}

Viruses are frequently identified in the respiratory tract of HIV-infected patients with ARF that required ICU admission, but with a non-viral copathogen in two-thirds of cases. Rhinovirus is the predominant viral specie; its prevalence is highest in patients with a CD4 lymphocyte count below 200 cells $/ \mu \mathrm{L}$.

\section{Supplementary information}

Supplementary information accompanies this paper at https://doi. org/10.1186/s13613-020-00738-9.

Additional file 1. Additional information on Material and methods, Table S1 (Panels of MPCR kits used in the two participating ICUs over the 6-year study period), Table S2 (Microbiological investigations performed in $123 \mathrm{HIV}$-infected patients admitted to the ICU for acute respiratory failure, according to the diagnosis of respiratory virus-associated infection), Table S3 (Baseline characteristics, behavior during ICU stay, and outcome of $123 \mathrm{HIV}$-infected patients admitted to the ICU for acute respiratory failure, according to the diagnosis of respiratory virus-associated infection), Table S4 (Multivariate analysis of the risk factors for death at Day-28 in 123 HIV-infected patients admitted to the ICU for acute respiratory failure), Figure S1 (Distribution of the microbiological documentations in $123 \mathrm{HIV}$ infected patients admitted to the ICU for acute respiratory failure), Figure S2 (Seasonal distribution of viral documentations).

\section{Abbreviations}

ARF: Acute respiratory failure; BAL: Bronchoalveolar lavage; CMV: Cytomegalovirus; COPD: Chronic obstructive pulmonary disease; ESM: Electronic supplementary material; HIV: Human immunodeficiency virus; ICU: Intensive care unit; LRT: Low respiratory tract; $\mathrm{mPCR}$ : Multiple polymerase chain reaction; NP: NasoPharyngeal; PCP: Pneumocystis jirovecii pneumonia; SAPS II: Simplified Acute Physiology Score; SOFA: Sepsis-related Organ Failure Assessment; WHO: World Health Organization.

\section{Acknowledgements}

None.

\section{Authors' contributions}

GV had full access to all of the data in the study and takes responsibility for the integrity of the data and the accuracy of the data analysis, including and especially any adverse effects. AE participated in the design of the study, participated in the data acquisition, analysis and interpretation, and the statistical analysis, and drafted the manuscript. JP, BV, AS, LB, QP, JP and VL participated in the data acquisition, analysis and interpretation, and helped to revise the manuscript. RS participated in the data analysis and interpretation, and the statistical analysis. MF and JFT participated in the design of the study, participated in the data analysis and interpretation, and helped to revise the manuscript. GV designed the study, participated in the data analysis and interpretation, and the statistical analysis, and revised the manuscript. All authors read and approved the final manuscript.

\section{Funding}

None.

Availability of data and materials

Data and materials supporting the findings of this study can be entirely shared if asked.

\section{Consent for publication}

Not applicable. 


\section{Competing interests}

The authors have reported that no potential conflicts of interest exist with any companies/organizations whose products or services may be discussed in this article.

\section{Author details}

1 Assistance Publique - Hôpitaux de Paris, Service de médecine intensive réanimation, Hôpital Tenon, Sorbonne Université, Paris, France. ${ }^{2}$ Assistance Publique - Hôpitaux de Paris, Service de virologie, Hôpital Bichat, Université de Paris, Paris, France. ${ }^{3}$ UMR 1137-IAME Team 5-DeSCID: Decision SCiences in Infectious Diseases control and care, INSERM, Université de Paris, Paris, France. ${ }^{4}$ INSERM, Saint-Antoine Research Center (CRSA), Assistance Publique - Hôpitaux de Paris, Département de virologie site Trousseau, Sorbonne Université, Paris, France. ${ }^{5}$ Assistance Publique - Hôpitaux de Paris, Service de réanimation médicale et infectieuse, Hôpital Bichat, Université de Paris, Paris, France. ${ }^{6}$ Groupe de Recherche Clinique GRC05 CARMAS, Institut Mondor de recherche biomédicale, INSERM, Université Paris Est, Créteil, France.

Received: 30 April 2020 Accepted: 6 September 2020

Published online: 14 September 2020

\section{References}

1. Chiang $\mathrm{H}-\mathrm{H}$, et al. Admissions to intensive care unit of HIV-infected patients in the era of highly active antiretroviral therapy: etiology and prognostic factors. Crit Care. 2011;15:R202.

2. Barbier F, et al. Etiologies and outcome of acute respiratory failure in HIVinfected patients. Intensive Care Med. 2009;35:1678-86.

3. Barbier F, et al. Temporal trends in critical events complicating HIV infection: 1999-2010 multicentre cohort study in France. Intensive Care Med. 2014;40:1906-15.

4. Powell K, et al. Survival for patients with HIV admitted to the ICU continues to improve in the current era of combination antiretroviral therapy. Chest. 2009:135:11-7.

5. Benito N, Moreno A, Miro JM, Torres A. Pulmonary infections in HIV-infected patients: an update in the 21st century. Eur Respir J. 2012;39:730-45

6. Crothers $\mathrm{K}$, et al. HIV infection and risk for incident pulmonary diseases in the combination antiretroviral therapy era. Am J Respir Crit Care Med. 2011;183:388-95.

7. Daubin C, et al. Epidemiology and clinical outcome of virus-positive respiratory samples in ventilated patients: a prospective cohort study. Crit Care. 2006;10:R142.

8. van Someren Gréve F, et al. Respiratory viruses in invasively ventilated critically ill patients - a prospective multicenter observational study. Crit Care Med. 2018;46:29-36.

9. Voiriot $\mathrm{G}$, et al. Viral-bacterial coinfection affects the presentation and alters the prognosis of severe community-acquired pneumonia. Crit Care 2016:20:375.

10. Karhu J, Ala-Kokko TI, Vuorinen T, Ohtonen P, Syrjälä H. Lower respiratory tract virus findings in mechanically ventilated patients with severe community-acquired pneumonia. Clin Infect Dis. 2014;59:62-70.

11. Loubet $P$, et al. Impact of respiratory viruses in hospital-acquired pneumonia in the intensive care unit: a single-center retrospective study. J Clin Virol. 2017:91:52-7.

12. Cameron RJ, et al. Virus infection in exacerbations of chronic obstructive pulmonary disease requiring ventilation. Intensive Care Med. 2006;32:1022-9.

13. Daubin C, et al. Procalcitonin algorithm to guide initial antibiotic therapy in acute exacerbations of COPD admitted to the ICU: a randomized multicenter study. Intensive Care Med. 2018;44:428-37.

14. Tan WC, et al. Epidemiology of respiratory viruses in patients hospitalized with near-fatal asthma, acute exacerbations of asthma, or chronic obstructive pulmonary disease. Am J Med. 2003;115:272-7.

15. Byington $\mathrm{CL}$, et al. Community surveillance of respiratory viruses among families in the utah better identification of germs-longitudinal viral epidemiology (BIG-LoVE) study. Clin Infect Dis. 2015;61:1217-24.

16. Jain $\mathrm{S}$, et al. Community-acquired pneumonia requiring hospitalization among U.S. adults. N Engl J Med. 2015;373:415-27.
17. Legoff J, et al. Clinical significance of upper airway virus detection in critically ill hematology patients. Am J Respir Crit Care Med. 2019;199:518-28.

18. Chemaly RF, Shah DP, Boeckh MJ. Management of respiratory viral infections in hematopoietic cell transplant recipients and patients with hematologic malignancies. Clin Infect Dis. 2014;59(Suppl 5):S344-51.

19. Figueiredo-Mello C, Naucler P, Negra MD, Levin AS. Prospective etiological investigation of community-acquired pulmonary infections in hospitalized people living with HIV. Medicine (Baltimore). 2017;96:e5778.

20. Garbino J, Inoubli S, Mossdorf E, Weber R, Tamm M, Soccal P, Aubert JD, Bridevaux PO, Tapparel C, Kaiser L, Swiss HIV Cohort Study. Respiratory viruses in HIV-infected patients with suspected respiratory opportunistic infection. AIDS. 2008;22(6):701-5.

21. Khouli H, Afrasiabi A, Shibli M, Hajal R, Barrett CR, Homel P. Outcome of critically ill human immunodeficiency virus-infected patients in the era of highly active antiretroviral therapy. J Intensive Care Med. 2005;20(6):327-33.

22. Dickson SJ, et al. Survival of HIV-infected patients in the intensive care unit in the era of highly active antiretroviral therapy. Thorax. 2007;62:964-8

23. Maartens G, Griesel R, Dube F, Nicol M, Mendelson M. Etiology of pulmonary infections in human immunodeficiency virus-infected inpatients using sputum multiplex real-time polymerase chain reaction. Clin Infect Dis. 2019. https://doi.org/10.1093/cid/ciz332.

24. Rossouw TM, Anderson R, Feldman C. Impact of HIV infection and smoking on lung immunity and related disorders. Eur Respir J. 2015;46:1781-95.

25. Chand HS, et al. Cigarette smoke and HIV synergistically affect lung pathology in cynomolgus macaques. J Clin Invest. 2018;128:5428-33.

26. Wilkinson TMA, et al. A prospective, observational cohort study of the seasonal dynamics of airway pathogens in the aetiology of exacerbations in COPD. Thorax. 2017;72:919-27.

27. Eddleston J, Lee RU, Doerner AM, Herschbach J, Zuraw BL. Cigarette smoke decreases innate responses of epithelial cells to rhinovirus infection. Am J Respir Cell Mol Biol. 2011;44:118-26.

28. Wu W, et al. Cigarette smoke attenuates the RIG-l-initiated innate antiviral response to influenza infection in two murine models. Am J Physiol Lung Cell Mol Physiol. 2014;307:L848-58.

29. Castro SM, Chakraborty K, Guerrero-Plata A. Cigarette smoke suppresses TLR-7 stimulation in response to virus infection in plasmacytoid dendritic cells. Toxicol In Vitro BIBRA. 2011;25:1106-13.

30. Hardelid P, Rait G, Gilbert R, Petersen I. Recording of influenza-like illness in UK primary care 1995-2013: cohort study. PLoS ONE. 2015;10:e0138659.

31. Adler AJ, Eames KTD, Funk S, Edmunds WJ. Incidence and risk factors for influenza-like-illness in the UK: online surveillance using Flusurvey. BMC Infect Dis. 2014;14:232.

32. Annamalay AA, et al. Respiratory viruses in young South African children with acute lower respiratory infections and interactions with HIV. J Clin Virol. 2016:81:58-63.

33. O'Callaghan-Gordo C, et al. Etiology and epidemiology of viral pneumonia among hospitalized children in rural Mozambique: a malaria endemic area with high prevalence of human immunodeficiency virus. Pediatr Infect Dis J. 2011:30:39-44.

34. Kok J, et al. Pandemic (H1N1) 2009 influenza virus seroconversion rates in HIV-infected individuals. J Acquir Immune Defic Syndr. 2011;1999(56):91-4

35. Wiemken T, et al. Incidence of respiratory viruses in patients with community-acquired pneumonia admitted to the intensive care unit: results from the Severe Influenza Pneumonia Surveillance (SIPS) project. Eur J Clin Microbiol Infect Dis. 2013;32:705-10.

36. Nunes MC, et al. Clinical epidemiology of bocavirus, rhinovirus, two polyomaviruses and four coronaviruses in HIV-infected and HIV-uninfected South African children. PLoS ONE. 2014;9:e86448.

37. Hammond SP, et al. Respiratory virus detection in immunocompromised patients with FilmArray respiratory panel compared to conventional methods. J Clin Microbiol. 2012;50:3216-21.

38. Camps Serra M, et al. Virological diagnosis in community-acquired pneumonia in immunocompromised patients. Eur Respir J. 2008;31:618-24.

39. Zlateva KT, et al. Prolonged shedding of rhinovirus and re-infection in adults with respiratory tract illness. Eur Respir J. 2014;44:169-77. 
40. Kaiser $L$, et al. Chronic rhinoviral infection in lung transplant recipients. Am J Respir Crit Care Med. 2006;174:1392-9.

41. Pathak AK, Adams RH, Shah NC, Gustin KE. Persistent human rhinovirus type $\mathrm{C}$ infection of the lower respiratory tract in a pediatric cord blood transplant recipient. Bone Marrow Transplant. 2013:48:747-8.

42. Piralla A, et al. Persistent rhinovirus infection in pediatric hematopoietic stem cell transplant recipients with impaired cellular immunity. J Clin Virol. 2015;67:38-42.

43. Burk M, El-Kersh K, Saad M, Wiemken T, Ramirez J, Cavallazzi R. Viral infection in community-acquired pneumonia: a systematic review and meta-analysis. Eur Respir Rev. 2016;25(140):178-88.

44. Blevins LK, Wren JT, Holbrook BC, Hayward SL, Swords WE, Parks GD, Alexander-Miller MA. Coinfection with Streptococcus pneumoniae negatively modulates the size and composition of the ongoing influenza-specific CD8 ${ }^{+}$T cell response. J Immunol. 2014;193(10):5076-87.

45. Jamieson AM, Pasman L, Yu S, Gamradt P, Homer RJ, Decker T, Medzhitov R. Role of tissue protection in lethal respiratory viral-bacterial coinfection. Science. 2013;340(6137):1230-4.

46. Iverson AR, Boyd KL, McAuley JL, Plano LR, Hart ME, McCullers JA. Influenza virus primes mice for pneumonia from Staphylococcus aureus. J Infect Dis. 2011;203(6):880-8.
47. Wiley JA, Harmsen AG. Pneumocystis infection enhances antibodymediated resistance to a subsequent influenza infection. J Immunol. 2008;180(8):5613-24.

48. Philippot Q, Labbé V, Pichon J, Djibré M, Fartoukh M, Voiriot G. Diagnosis and management of respiratory viruses in critically ill adult patients: an international survey of knowledge and practice among intensivists. Ann Intensive Care. 2020;10(1):50.

49. Musher DM, Montoya R, Wanahita A. Diagnostic value of microscopic examination of Gram-stained sputum and sputum cultures in patients with bacteremic pneumococcal pneumonia. Clin Infect Dis. 2004;39(2):165-9.

50. Jeong JH, Kim KH, Jeong SH, Park JW, Lee SM, Seo YH. Comparison of sputum and nasopharyngeal swabs for detection of respiratory viruses. J Med Virol. 2014:86(12):2122-7.

\section{Publisher's Note}

Springer Nature remains neutral with regard to jurisdictional claims in published maps and institutional affiliations.

\section{Submit your manuscript to a SpringerOpen ${ }^{\circ}$ journal and benefit from:}

- Convenient online submission

- Rigorous peer review

- Open access: articles freely available online

- High visibility within the field

- Retaining the copyright to your article

Submit your next manuscript at $\boldsymbol{\nabla}$ springeropen.com 